\title{
Recent Space PV Concentrator Advances: More Robust, Lighter, and Easier to Track
}

\author{
Mark O’Neill ${ }^{1}$, A.J. McDanal ${ }^{1}$, Henry Brandhorst ${ }^{2}$, Kevin Schmid ${ }^{3}$, \\ Peter LaCorte ${ }^{3}$, Michael Piszczor ${ }^{4}$, Matt Myers ${ }^{4}$ \\ ${ }^{1}$ Mark O’Neill, LLC, Keller, TX 76248, ${ }^{2}$ Carbon-Free Energy, LLC, Auburn, AL 36830, ${ }^{3}$ Deployable \\ Space Systems, Inc., Goleta, CA 93117, ${ }^{4}$ NASA Glenn Research Center, Cleveland, OH 44135
}

\begin{abstract}
Over the past three years, the authors have collaborated on several significant advances in space photovoltaic concentrator technology, including a far more robust Fresnel lens for sunlight concentration, improved color-mixing features for the lens to minimize chromatic aberration losses for next-generation 4-junction and 6-junction IMM cells, a new approach to suntracking requiring only one axis of rotation even in the presence of large beta angles $\left(\right.$ e.g., $\pm 50^{\circ}$ ), a new waste heat radiator made of graphene, with $80-90 \%$ reduction in mass, and a new platform for deployment and support on orbit (SOLAROSA). These patent-pending advances are described in this paper.
\end{abstract}

Index Terms - concentrator, Fresnel lens, graphene, inverted metamorphic (IMM) cells, Solar Optical Lens Architecture on Roll-Out Solar Array (SOLAROSA).

\section{INTRODUCTION AND BACKGROUND}

Refractive concentrators for space power have been flown successfully for more than 20 years, as shown in Fig. 1.
Point-focus versions include the mini-dome lens flight test on PASP+ in 1994-95 [1]. Line-focus versions include the award-winning SCARLET array on Deep Space 1 in 19982001 [2]. The stretched lens array (SLA) built upon the success of SCARLET with a much lighter array, compatible with either a rigid-panel array architecture or a flexible-blanket array architecture [3]. An SLA flight experiment (Stretched Lens Array Technology Experiment, SLATE) flew on TacSat 4 in 2011-2012, achieving excellent performance until a mechanical failure of the lens due to radiation-induced embrittlement of the monolithic silicone material. The lens began to tear in the $7^{\text {th }}$ month and tore all the way across in the $13^{\text {th }}$ month of the mission [4]. Since that lens failure, our team has worked on a number of more robust lens approaches to replace the weak monolithic silicone lens construction.

The refractive concentrators shown in Fig. 1 all required full two-axis sun tracking for proper focusing on orbit. This limita-

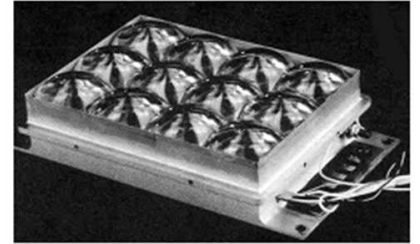

Launched in 1994: Mini-Dome Lens Array on PV Array Space Power Plus (PASP-PIUS) Provided Best

Performance and Least Degradation of 12 Advanced Solar Arrays

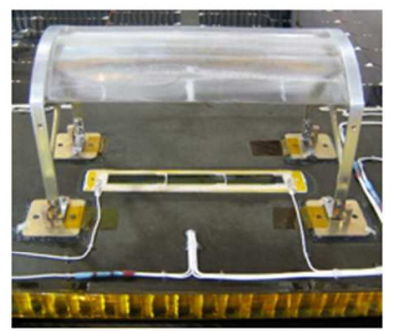

Launched in 2011: SLA Technology Experiment (SLATE) on TacSat 4 Demonstrated Less than $1 / 2$ the Degradation Rate of One-Sun Cells During First 6 Months on Orbit Before Lens Mechanical Failure (Problem Now Solved)

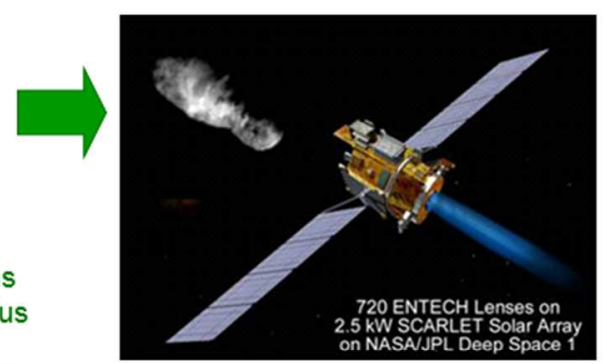

Launched in 1998: Solar Concentrator Array with Refractive Linear Element Technology (SCARLET) 2.5 kW Array on Deep Space 1 Performed Flawlessly for 38-Month Mission on First Spacecraft Powered by Triple-Junction Cells
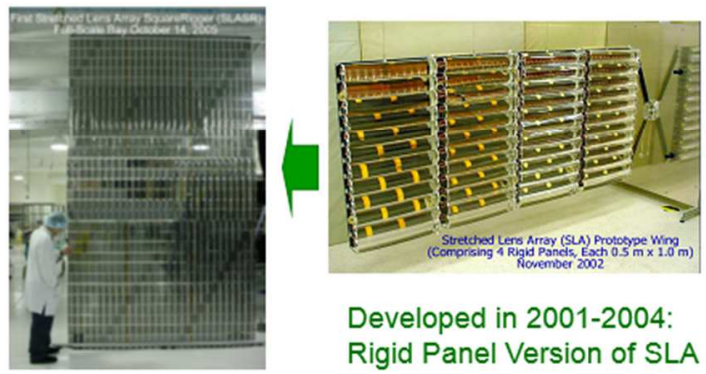

Developed in 2001-2004: Rigid Panel Version of SLA

Developed in 2003-2014: Ultralight SLA $\left(>300 \mathrm{~W} / \mathrm{m}^{2},>350 \mathrm{~W} / \mathrm{kg},>80 \mathrm{~kW} / \mathrm{m}^{3}\right.$ )

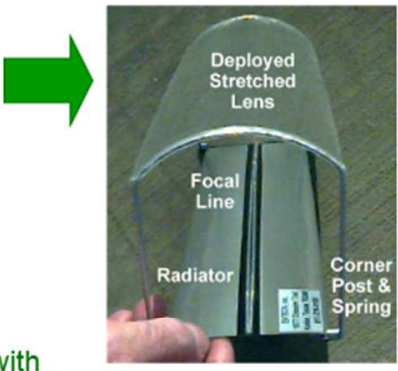

Stretched Lens Array Invented in 1998
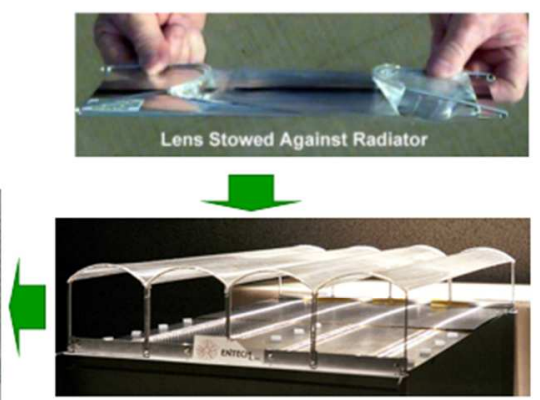

Developed in 1999-2000: Flexible-Blanket Version of Stretched Lens Array (SLA)

Fig. 1. Refractive Concentrators for Space Power - A Long Heritage of Success with 1 Glitch. 
tion was a major disadvantage for many planned missions, from GEO communication satellites to solar electric propulsion (SEP) spiral-out missions from LEO to GEO [5]. To overcome this disadvantage, a new approach has been developed to enable single-axis sun tracking with very large beta angles (e.g., $\left.\pm 50^{\circ}\right)$.

Multi-junction solar cells have long been used in refractive concentrators, from stacked dual-junction cells on PASP+ to monolithic triple-junction cells on SCARLET. To overcome losses due to chromatic aberration in the SCARLET cells, a color-mixing lens was developed [6]. However, as cells continue to incorporate more junctions, the older form of color mixing has proven inadequate, and a new improved method has been developed and proven.

Waste heat has always been an issue for refractive concentrators, requiring a radiator to spread and radiate the heat to deep space to keep the cell cool and efficient. Carbon-fiber sheets and aluminum sheets have been the best radiator materials until recently. However, the newly developed graphene material is now being incorporated into the latest refractive concentrators with major reductions in mass [7].

As the lens, cell, and radiator improvements have been identified and developed, a more efficient platform for deployment and support of refractive concentrators has been needed, and the roll-out solar array (ROSA) pioneered by Deployable Space Systems has been adapted to the latest refractive concentrator technology to form SOLAROSA [8].

Each of these improvements is discussed separately below, and the combined effect on array performance metrics is then presented.

\section{NEW MoRe RobUST FRESNEL LENSES}

In the past two years, we have designed, developed, tooled, and made two new lenses, shown in Fig. 2. Both of these lenses are optimized to operate on a single-axis sun-tracking platform while accommodating $\pm 50^{\circ}$ beta angle variations and $\pm 2^{\circ}$ alpha angle variations without significant loss of power. One lens is arched shape and achieves 6.7X geometric concentration ratio (GCR), while the other is flat and achieves

- Both Lenses Optimized for $\pm 50^{\circ}$ Beta and $\pm 2^{\circ}$ Alpha Tolerance

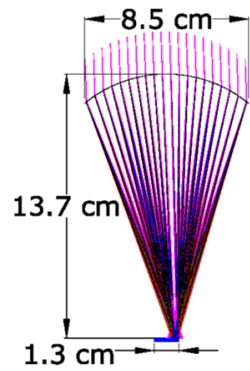

$0^{\circ}$ Beta, $2^{\circ}$ Alpha Above $50^{\circ}$ Beta, $2^{\circ}$ Alpha Right
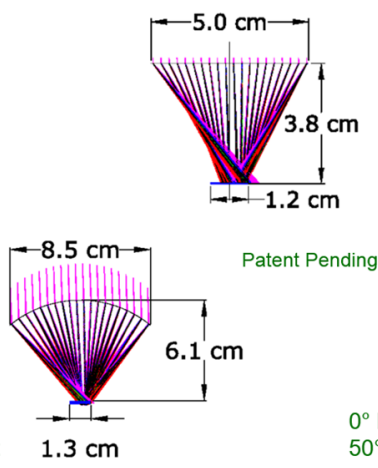

Patent Pending $6.1 \mathrm{~cm}$
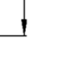

Fig. 2. Two New Lenses Tooled and Ready: $6.7 \mathrm{X} 8.5 \mathrm{~cm}$-Wide Arched Lens and 4.2X $5.0 \mathrm{~cm}$-Wide Flat Lens.
4.2X GCR. The arched lens has the same aperture width as the earlier SCARLET and SLA lenses, while the flat lens has a smaller aperture width to allow for a thinner and lighter radiator with reduced cell temperature.

To make the lens more robust, we are exploring two different approaches which can be applied to either the arched lens or the flat lens. The first approach uses a transparent superstrate, either polymer or glass, to support the weak silicone prisms. The second approach uses an embedded mesh, either metal or glass or graphene, to strengthen the weak silicone material. Both approaches are shown in Fig. 3.
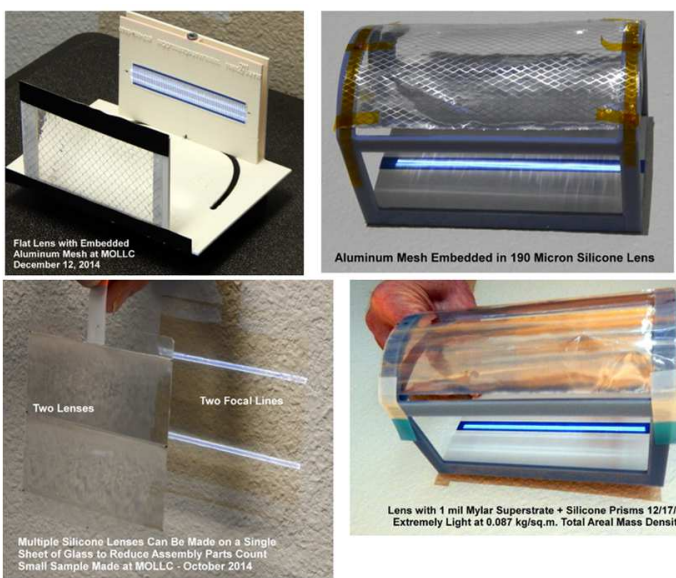

Top Row:

Silicone

Lenses with

Embedded

Aluminum

Mesh

Patent Pending

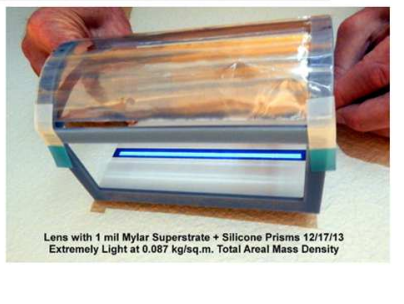

Bottom Row Silicone Prisms on Transparent Superstrates

Fig. 3. New Strengthened Material Approaches Save Mass and Make More Robust Lens.

In these new lens approaches, the strong superstrate or the strong mesh carries the lengthwise tension load rather than the weak silicone material, reducing the strain and improving the tensile strength and tear resistance of the lens by orders of magnitude.

The new strengthened lenses are also lighter and easier to manufacture than previous monolithic lenses. Using flexible plastic tooling, the silicone prismatic pattern is cast and cured directly against either the transparent superstrate or the embedded mesh, in a simple, highly scalable process, as shown

\section{Total Lens Thickness $=$ Superstrate + Prisms}
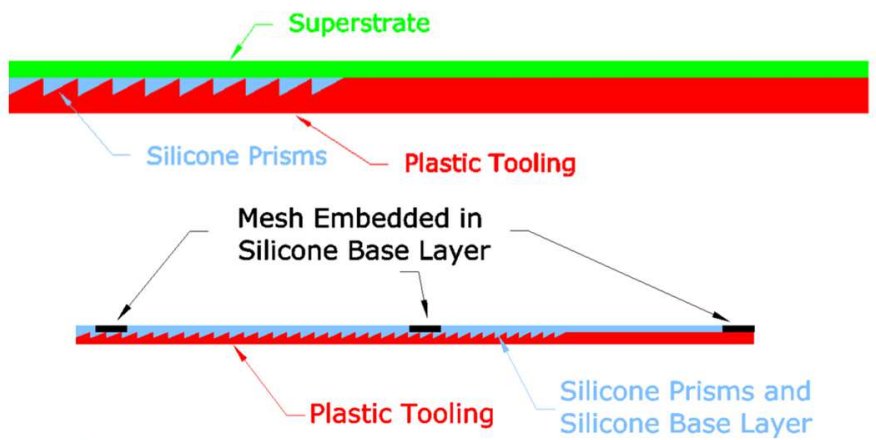

Total Lens Thickness $=$ Mesh + Prisms

Fig. 4. Robust Lenses: Silicone Prisms on Transparent Superstrate or Mesh-Reinforced Silicone Lens. 
in Fig. 4. After curing, the flexible plastic tool is peeled off the new strengthened lens.

Fig. 5 shows the areal mass density $\left(\mathrm{kg} / \mathrm{m}^{2}\right)$ of selected new strengthened lenses in flat form. Arched lenses would be about $8 \%$ heavier per unit aperture because of the added arc length. The new lenses are significantly lighter than the old SCARLET lens shown as the top bar.

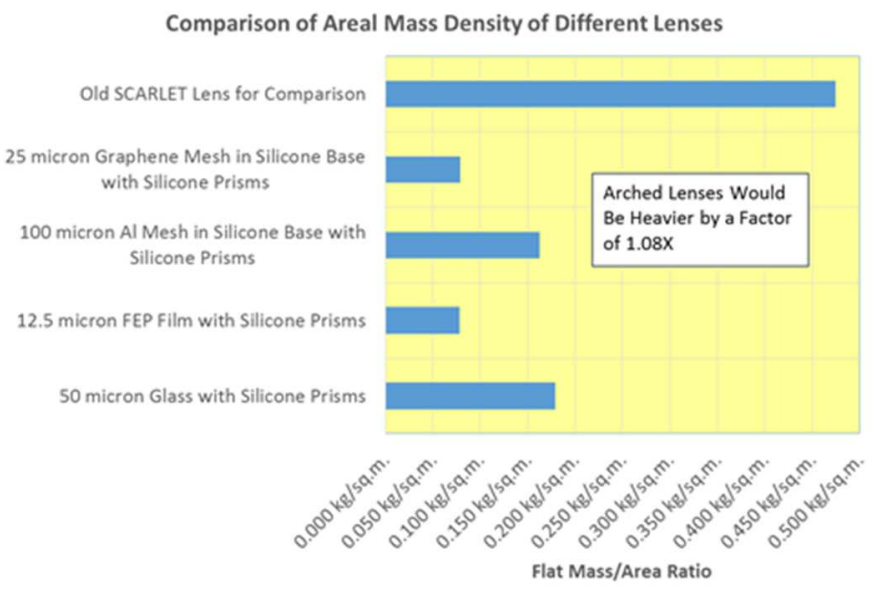

Fig. 5. New Strengthened Material Approaches Save Mass and Make a More Robust Lens.

All of the new lens approaches using polymer film superstrates or mesh embedded in silicone as the exposed outer layer of the lens will need a coating to provide protection from both solar ultraviolet radiation and low energy charged particle radiation. Fortunately, we have successfully flown such coatings on the PASP+ lenses and the TacSat 4 lens, with good optical performance results. The new lens approach using silicone prisms molded onto ceria-doped microsheet glass (QioptiQ CMG 50 microns thick) will not require such a coating, as the CMG provides protection against both space environmental effects. Recent radiation testing has proven the robustness of the silicone prisms on CMG glass approach, which is our current preferred lens material combination.

\section{NEW SINGLE-AXIS SUN-TRACKING APPROACH USING ARTiculating RECEIVERS TO ACCOMMODATE LARGE BETA ANGLES}

We have recently developed a novel approach to accommodate large beta angles without rotating the solar array about a second axis. This approach utilizes articulating photovoltaic receivers to enable a relatively large geometric concentration ratio (GCR) while only rotating the array about a single axis to follow the sun on orbit. The lens design is optimized for this unusual seasonal articulation of the receiver to place the receiver in the proper location to capture the sharp focal line produced by the lens. Fig. 6 shows the extents of the receiver motion for both an arched lens and a flat lens. Note that the receiver moves in two directions, changing the vertical
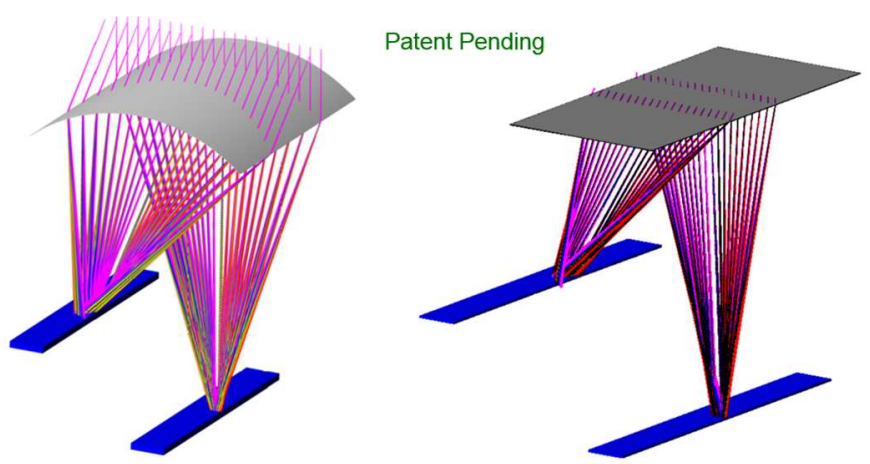

A video showing more views is available at www.markoneill.com/movies. html

Fig. 6 New Lens Design with Articulating Receiver Enables Single-Axis Tracking with $\pm 50^{\circ}$ Beta Angle Tolerance.

distance between lens and receiver, and changing the longitudinal location of receiver relative to lens.

Arched lenses offer better optical performance than flat lenses, because both the curved smooth outer surface and the prismatic inner surface contribute to the refraction. But flat lenses are more compatible with the use of ultrathin ceriadoped glass as the superstrate for the silicone prisms, and flat lenses are a little lighter than arched lenses due to their smaller surface area. Optimization analysis leads to the limits on GCR for a selected combination of alpha angle tolerance and beta angle tolerance. GEO missions must accommodate the annual solar declination angle change, which leads to beta angles of about $\pm 24^{\circ}$. Spiral-out SEP missions from LEO to GEO or lunar orbit or beyond often take many months to complete their orbit raising, leading to seasonal changes in the solar declination angle combined with the initial orbital inclination leading to beta angle variations on the order of $\pm 50^{\circ}$ for a Canaveral launch [5]. The achievable GCR for both arched and flat lenses is shown in Fig. 7 for such these two beta angle tolerances.

The selected designs are circled in Fig. 7. These designs also correspond to the two new lens designs previously shown in Fig. 2 and Fig. 6.

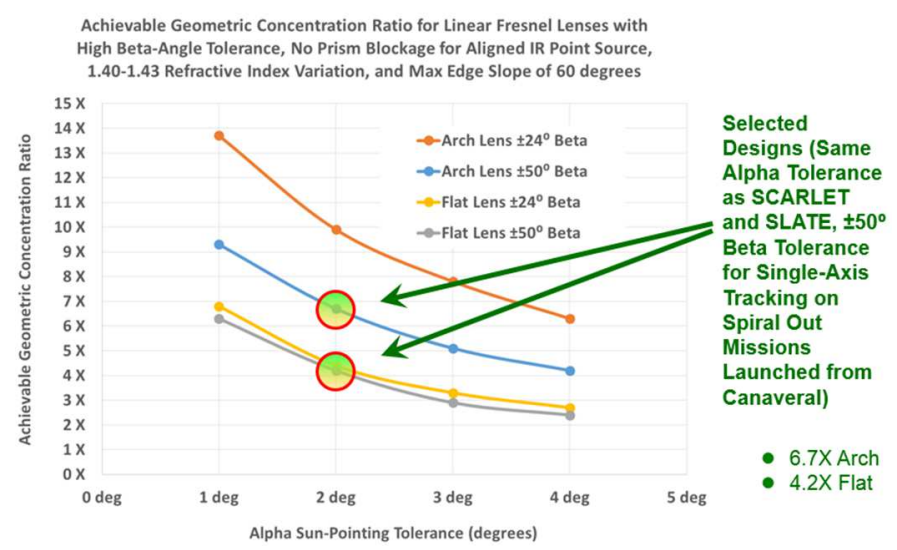

Fig. 7. Achievable Geometric Concentration Ratio (GCR) for HighBeta-Angle-Tolerant Lenses with Articulating Receivers 


\section{NEW COLOR-MiXING LENS TECHNOLOGY}

The color-mixing lens approach [6] used for the SCARLET lenses and the earlier SLA lenses was adequate for 2-junction and 3-junction cells, but not for 4-junction and 6-junction cells. Therefore, a new method has been developed to provide better color-mixing. The original patented approach overlapped "blue" and "red" light by a fixed amount from each pair of neighboring prisms. The new approach overlaps "blue" and "red" light by varying amounts for each triplet of neighboring prisms. By using a three-part overlap, better results are achieved than by using two-part overlap, and analyses have been performed for 4-junction and 6-junction cells, with typical results shown in Fig. 8 for the $5.0 \mathrm{~cm}$ flat lens focusing onto a $1.2 \mathrm{~cm}$ wide 4-junction, using an extension of the analytical methods developed earlier [6]. Note that the new method results in less than $1 \%$ power loss for chromatic aberration in 4-junction cells. Recent testing under another program has validated the excellent performance of the new color-mixing lens approach in an even more-demanding application.

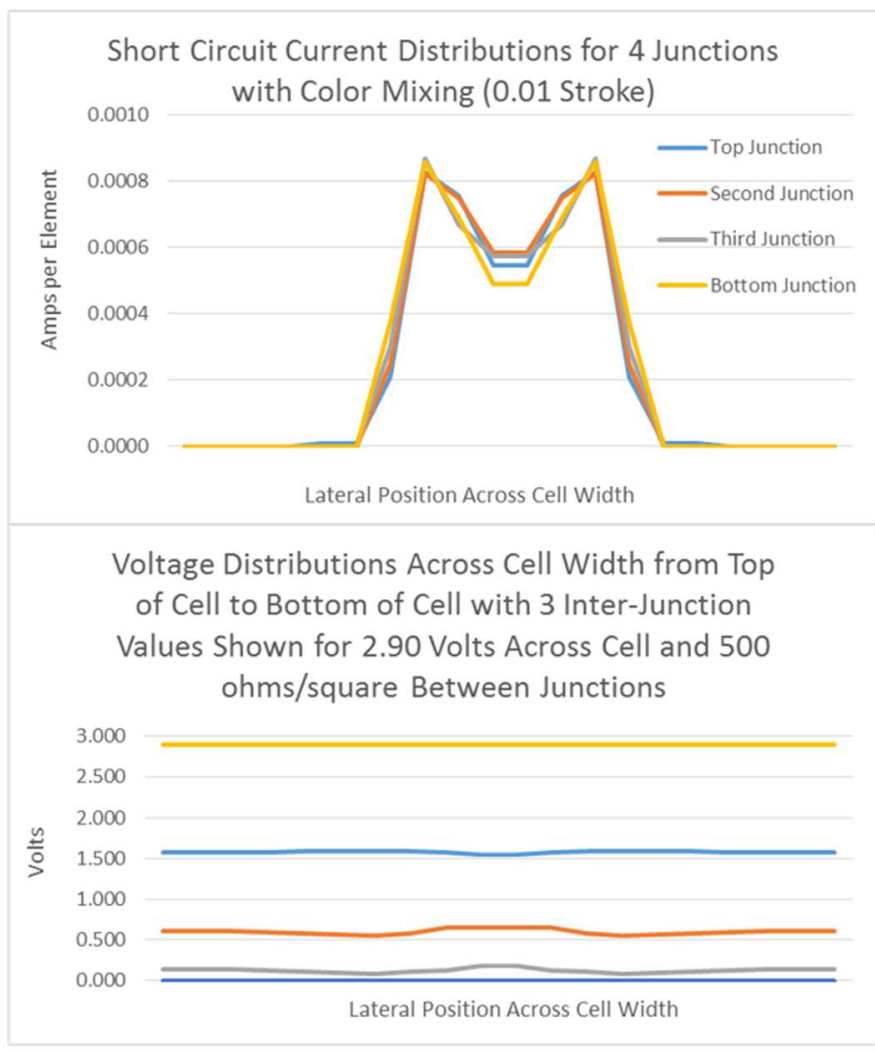

This calculation assumes a conservative 500 ohms/square resistance between junctions. Alex Haas (Emcore) and Sarah Kurtz (NREL) were consulted about this resistance value and this model. Both thought 500 ohms/square is conservative. Chromatic aberration power loss for this case $<1 \%$.

Fig. 8. New Color-Mixing Lens Design Approach Minimizes Chromatic Aberration Loss in 4-Junction IMM Cell.

\section{NEW GRAPHENE RADIATOR TECHNOLOGY}

For a refractive photovoltaic concentrator operating in space, the waste heat from the solar cell must be spread over a radiator area equal in extent to the lens aperture area, and then radiated to the space environment from both sides of the radiator. The radiated heat from the lens-side of the radiator encounters the lens as a radiation shield which reduces the effective emittance for that side of the radiator compared to a one-sun array. The radiated heat from the back-side of the radiator is unobstructed from reaching deep space. Albedo and black body radiation from nearby planets or other bodies add to the radiator heat load and increase the radiator temperature. The thermal model for a refractive concentrator is shown schematically in Fig. 9. The temperature gradient across the radiator from the solar cell to the adiabatic boundaries is minimized by keeping the lens aperture width small, which is why the present lenses have widths of only $5.0 \mathrm{~cm}$ and $8.5 \mathrm{~cm}$. Over the past three decades, the best radiator materials have been carbon-fiber-reinforced composite sheet and aluminum. With the ongoing revolutionary work in nanomaterials, a new radiator material has emerged, graphene, shown in Fig. 10. In terms of heat conduction per unit mass, graphene is $5 \mathrm{X}$ better than carbonfiber-reinforced composite sheet and $10 \mathrm{X}$ better than aluminum sheet. We are therefore incorporating graphene radiators into the next-generation refractive concentrator technology.

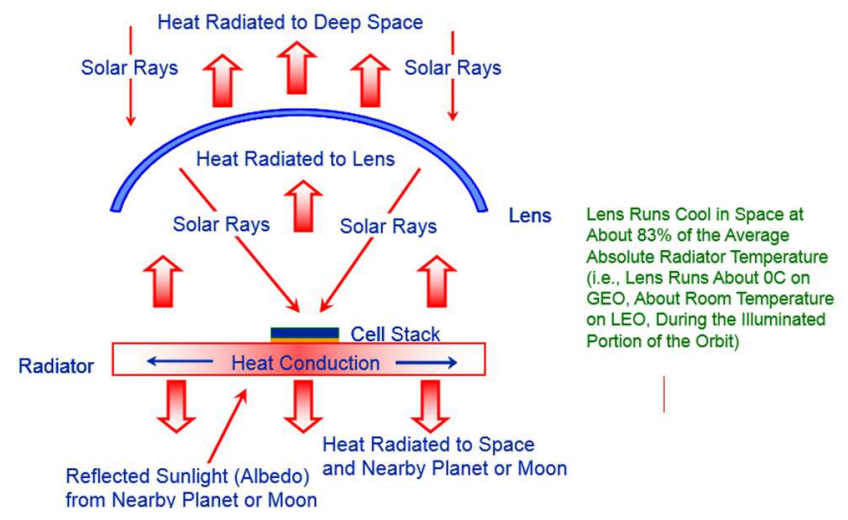

Fig. 9. Thermal Model of Refractive Concentrator in Space.

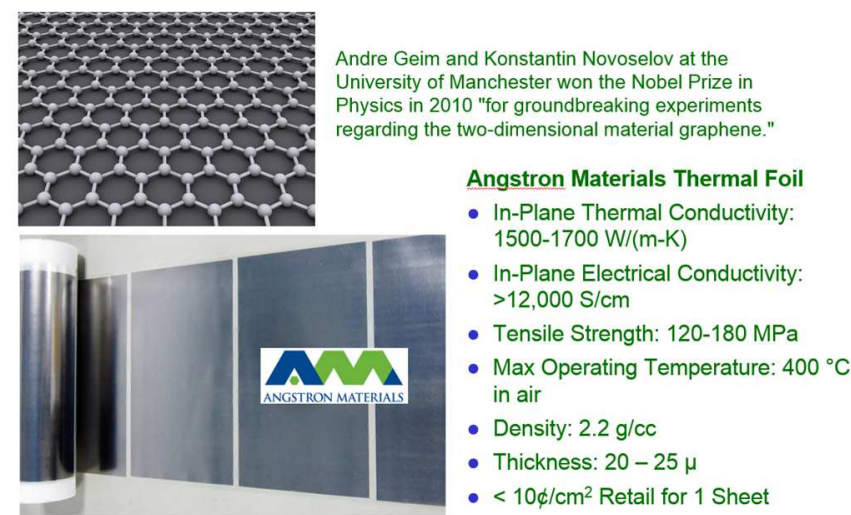

Fig. 10. Graphene Is an Atomic-Scale Hexagonal Lattice Made of Carbon Atoms Which Can Be Formed into a Thermal Foil. 
Thermal analysis of a 25 micron thick graphene radiator shows that the operating cell temperature on GEO will be less than $60^{\circ} \mathrm{C}$ for a flat lens refractive concentrator with $5.0 \mathrm{~cm}$ aperture width, as shown in Fig. 11. Note that the lateral gradient is less than $6^{\circ} \mathrm{C}$ for this new radiator material.

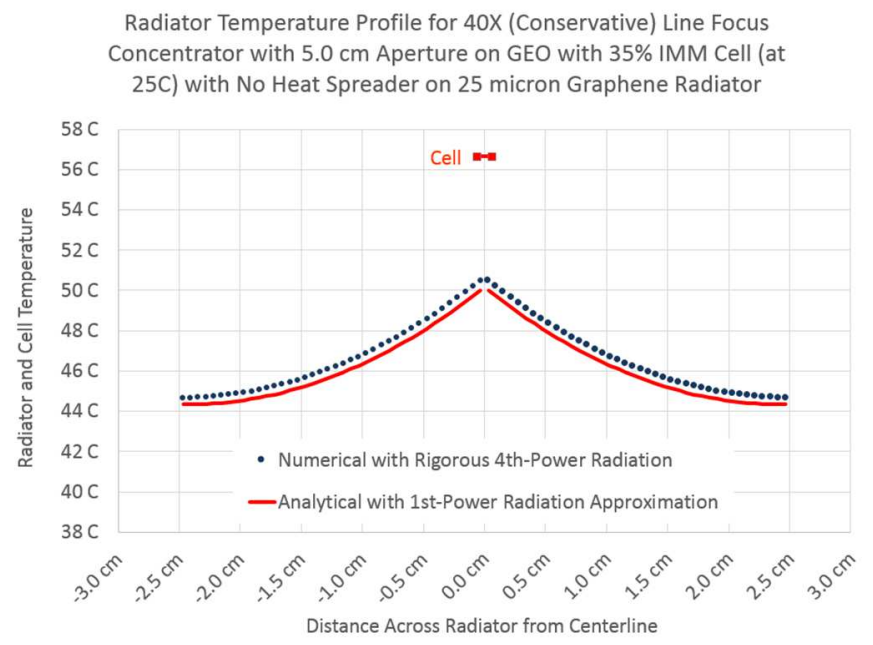

Fig. 11. Radiator Temperature with $25 \mu$ Graphene Radiator for 5.0 $\mathrm{cm}$ Lens Aperture.

VI. IMPACT OF THESE IMPROVEMENTS ON BLANKET METRICS

The impact of the improvements to refractive concentrator technology is significant. As shown in Fig. 12, the three key blanket elements of lens, photovoltaic receiver (with 150 micron equivalent cover glass shielding front and back), and radiator have a small enough combined areal mass density to enable a specific power for these components of well over $1,000 \mathrm{~W} / \mathrm{kg}$ with 4 -junction IMM cell technology. The mass of the deployment and support structure is not included in this estimate.

\section{NEW DEPLOYMENT AND SUPPORT PLATFORM}

To complement the new improved lens blanket and radiator/cell blanket, a new deployment and support structure is being developed based on the unique ROSA platform pioneered by Deployable Space Systems (DSS). The new platform is known as SOLAROSA. One schematic version of SOLAROSA is shown in the patent drawing reproduced in Fig. 13 [7].

\section{RECENT OPTICAL DEMONSTRATION OF THE NEW LENS AND SUN-TRACKING APPROACH}

The ability of the new lens to focus well at very high beta angles has been demonstrated with prototype hardware, as shown in Fig. 14. The preferred motion of the articulating receiver was also validated with this prototype hardware. By incorporating this relatively small seasonal articulation of the receiver relative to the lens into the single-axis sun-tracking SOLAROSA platform, excellent array performance will be maintained for beta angles from $-50^{\circ}$ to $+50^{\circ}$.

\begin{tabular}{|c|c|c|c|c|c|c|}
\hline \multicolumn{7}{|c|}{$\begin{array}{c}\text { Areal Mass Density for 4.15X SLA with Glass/Silicone Lens, Graphene Radiator Sheet, } \\
\text { and Photovoltaic Receiver Elements for IMM Cell with } 150 \text { micron (6 mil) Equivalent } \\
\text { Cover Glass Shielding Front and Back }\end{array}$} \\
\hline \multicolumn{2}{|r|}{ Geometric Concentration Ratio } & \multirow{3}{*}{\begin{tabular}{|c|}
$4.15 \mathrm{X}$ \\
$5.00 \mathrm{~cm}$ \\
$\begin{array}{c}\text { Element Area per } \\
\text { sq.m. A perture }\end{array}$ \\
\end{tabular}} & \multicolumn{3}{|c|}{ Physical Concentration Ratio } & \multirow{3}{*}{\begin{tabular}{|c|}
$3.12 \mathrm{X}$ \\
$1.60 \mathrm{~cm}$ \\
$\begin{array}{c}\text { Subtotals: } \\
\text { Mass/A perture }\end{array}$
\end{tabular}} \\
\hline \multirow{3}{*}{$\begin{array}{c}\text { Major } \\
\text { Subsystem }\end{array}$} & A perture Width & & \multirow{2}{*}{\begin{tabular}{|l|} 
Cell Width \\
Thickness \\
\end{tabular}} & \multirow{2}{*}{\begin{tabular}{|l|}
$1.40 \mathrm{~cm}$ \\
Density
\end{tabular}} & \multirow{2}{*}{$\begin{array}{l}\text { Receiver Width } \\
\text { Mass/A perture }\end{array}$} & \\
\hline & Element & & & & & \\
\hline & & (sq.m.) & $(\mathrm{cm})$ & $(\mathrm{g} / \mathrm{cu} . \mathrm{cm})$. & (kg/sq.m.) & (kg/sq.m.) \\
\hline Lens & 50 micron $\mathrm{CMG} / 50$ micron Silicone & 1.000 & 0.010 & 1.790 & 0.179 & 0.179 \\
\hline Radiator & Graphene Radiator & 1.000 & 0.003 & 2.200 & 0.055 & 0.055 \\
\hline & & & & & & \\
\hline \multirow{5}{*}{ Receiver } & Microsheet Cover Slide & 0.321 & 0.007 & 2.550 & 0.057 & \multirow{5}{*}{0.170} \\
\hline & Cover Slide Adhesive & 0.321 & 0.003 & 1.030 & 0.008 & \\
\hline & IMM Cell & 0.321 & 0.001 & 5.300 & 0.017 & \\
\hline & Thermally Conductive Adhesive (CV2946) & 0.321 & 0.013 & 1.500 & 0.064 & \\
\hline & Dielectric Film & 0.321 & 0.005 & 1.500 & 0.024 & \\
\hline \multicolumn{5}{|c|}{ Total Areal Mass Density: } & & $0.404 \mathrm{~kg} / \mathrm{sq} . \mathrm{m}$. \\
\hline \multicolumn{5}{|c|}{ SLA Blanket Specific Power for 35\% Cell at One-Sun (39\% Cell at Concentration) } & $1,186 \mathrm{~W} / \mathrm{kg}$ & \\
\hline $\begin{array}{l}100 \mu \text { Tall T } \\
\text { Layer with I }\end{array}$ & $\begin{array}{l}\text { iangular Prisms Fill Only Half Their } \\
\text { laterial and Weigh as } 50 \mu \text { Thickness }\end{array}$ & $1,186 \mathrm{~V}$ & I/kg Len & . & iver + & diator \\
\hline
\end{tabular}

Fig. 12. 4.15X Flat Lens Made from $50 \mu \mathrm{CMG}+100 \mu$ Silicone Prisms over 4-Junction IMM Receiver with Equivalent Shielding of $150 \mu$ CMG Coverglass Front and Back on $25 \mu$ Graphene Radiator 


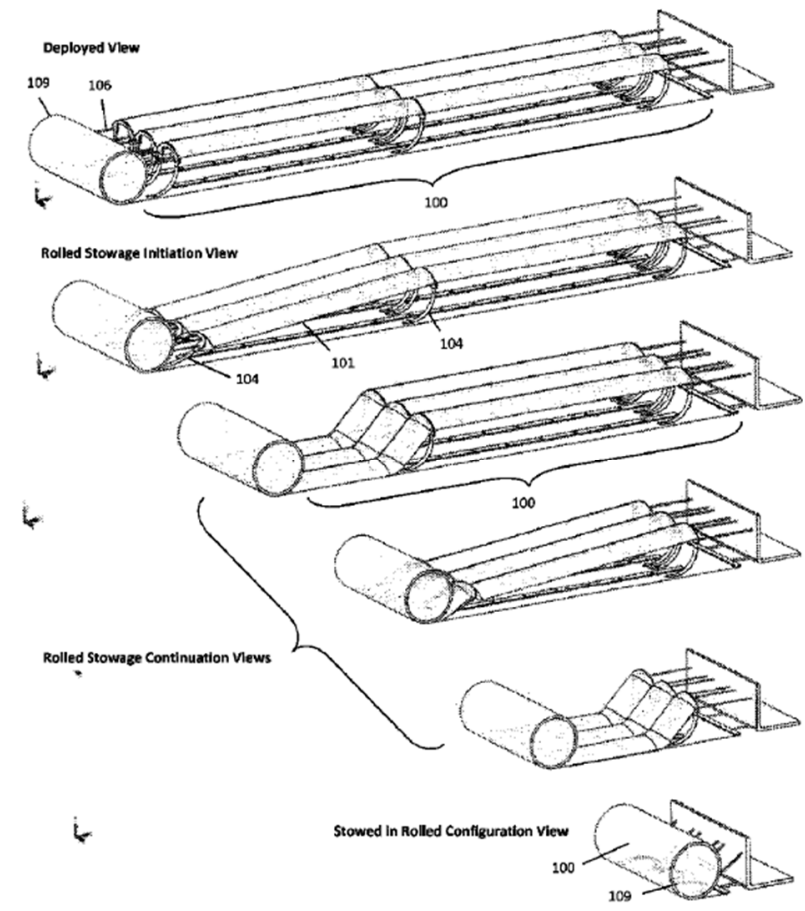

Fig. 13. SOLAROSA Platform for New Refractive Concentrator Technology.

\section{ACKNOWLEDGEMENT}

The advances in space refractive photovoltaic concentrator technology discussed in this paper were made possible in large part by several previous and ongoing NASA SBIR contracts.
- $\quad$ improved color-mixing features for the lens to minimize chromatic aberration losses for next-generation 4junction and 6-junction IMM cells

- a new approach to sun-tracking requiring only one axis of rotation even in the presence of large beta angles (e.g., $\pm 50^{\circ}$ )

- a new waste heat radiator made of graphene, with 80$90 \%$ reduction in mass, and

- a new platform for deployment and support on orbit (SOLAROSA).

\section{REFERENCES}

[1] Guidice, D.A., et al., "Photovoltaic Array Space Power Plus Diagnostics (PASP Plus) Experiment," USAF Philips Lab Space Technology Directorate, Report PL-TR-97-1013, March 1997.

[2] Allen, D.M., et al., "The SCARLET Light Concentrating Array," $25^{\text {th }}$ IEEE PVSC, 1996.

[3] Piszczor, M.F. et al., "Recent Technology Advances for the Stretched Lens Array (SLA), A Space Solar Array Offering State of the Art Performance at Low Cost and Ultra-Light Mass," 31st IEEE PVSC, 2005.

.[4] Jenkins, P. et al., "Initial Results from the TacSat-4 Solar Cell Experiment," 39th IEEE PVSC, 2013.

[5] Kerslake, T., et al., "Solar Electric Propulsion (SEP) Tug Power System Considerations," NASA/TM-2011-217197, 2011.

[6] O’Neill, M., "Line-Focus Optics for Multijunction Cells In Space Power Arrays," 25th IEEE PVSC, 1996.

[7] Xin, G. et al., "Large-Area Freestanding Graphene Paper for Superior Thermal Management," Advanced Materials, 2014.

[8] Spence, B., et al., "Rollable and Accordion Foldable Refractive Concentrator Space Solar Array Panel, U.S. Patent 8,636,253, 2014.

\section{CONCLUSIONS}

Significant advances in space photovoltaic concentrator technology have recently been made, including:

- a far more robust Fresnel lens for sunlight concentration

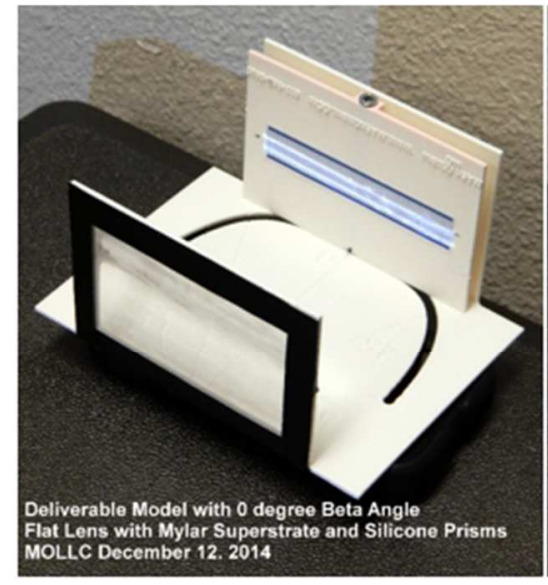

$$
\boldsymbol{\beta}=\mathbf{0}^{\circ}
$$

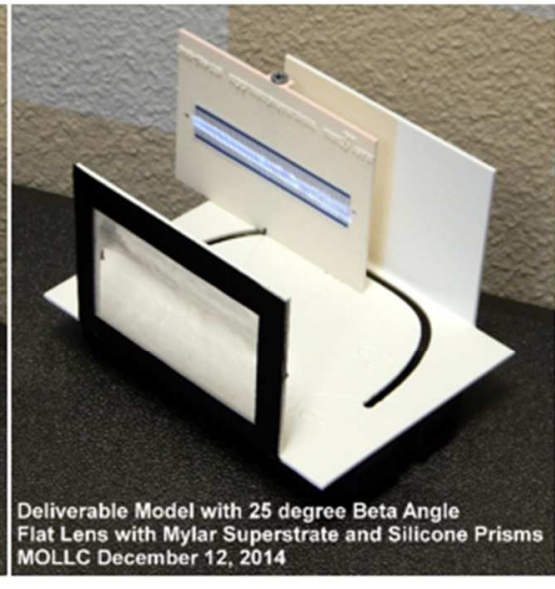

$\beta=-25^{\circ}$

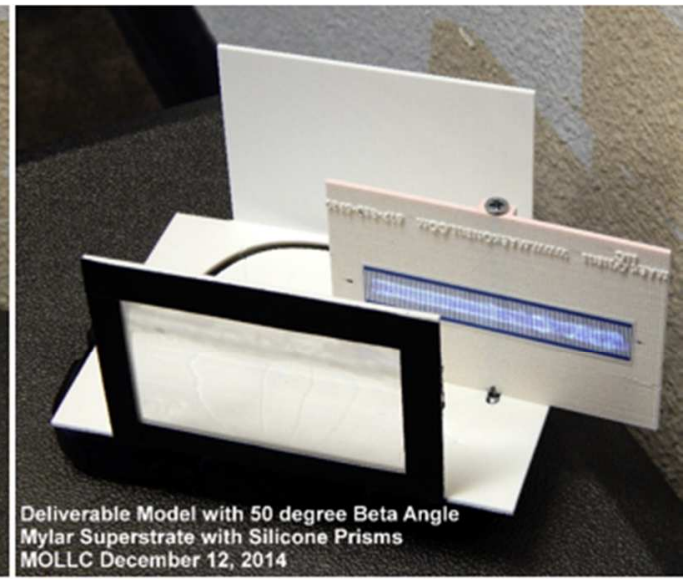

$\beta=+50^{\circ}$

Fig. 14. New Lens Design with Articulating Receiver Enables Single-Axis Tracking with $\pm 50^{\circ}$ Beta Angle Tolerance. 